\title{
Effects of Dietary Wheat Gluten Meal on Growth, Intestinal Morphology, and Microbiome in Juvenile Large Yellow croaker Larimichthys crocea
}

\author{
Fan X J, Yin H, Chai R Y, Shui X M, Huang J, Wang P* \\ National Engineering Research Center of Marine Facilities Aquaculture, Zhejiang Ocean \\ University, Zhoushan 316022, P.R. China
}

Key words: Larimichthys crocea; wheat gluten meal; growth performance; intestinal histology; intestinal microbiota

\begin{abstract}
Wheat gluten meal (WGM) was evaluated as a replacement of fish meal (FM) for juvenile Larimichthys crocea . FM was replaced by $0 \%, 25 \%, 50 \%, 75 \%$, and $100 \%$ of WGM (WGM0, WGM25, WGM50, WGM75, and WGM100, respectively). In addition, all diets except the control group were supplemented with amino acids. Fish were fed twice daily for 56 days. There were no significant differences in survival and feed conversion ratio (FCR) among all treatments $(P>0.05)$. WGM25, WGM50, and WGM75 groups had significantly higher specific growth rate (SGR) and weight gain ratio $(W G R)$ than those fed with WGMO $(P<0.05)$. There were no significant differences in mucosal thickness (MT), lamina propria width (LW), mucosal fold height $(\mathrm{MH})$, and goblet cell quantity of single hair (GC) for all the diets $(P>0.05)$. The indexes of Chao1, Shannon, Simpson, and Good coverage in fish fed with WGM0, WGM50, and WGM100 were not significantly affected $(\mathrm{P}>0.05)$. Firmicutes $(81.03 \sim 94.03 \%)$ were the dominant bacterial community in juvenile large yellow croaker. Compared with the WGMO group, the abundance of Firmicutes increased significantly, and Proteobacteria decreased significantly in the WGM100 group $(P<0.05)$. These results suggested that WGM could replace 366.3 $\mathrm{g} \mathrm{kg-1} \mathrm{FM} \mathrm{of} \mathrm{the} \mathrm{juvenile} \mathrm{large} \mathrm{yellow} \mathrm{croaker} \mathrm{diet.}$
\end{abstract}




\section{Introduction}

Globally, fisheries' landings have remained constant at about 90 million tons per annum for the past few decades, whereas aquaculture output has been increasing at the rate of $8 \%$ per annum, and currently supplies around 78 million tons (FAO, 2016). Fish meal (FM) is used as the primary protein source of world Aqua and Mari culture. Since the global supply of FM is insufficient to meet the demands of such a growing industry, there is significant interest in finding alternative protein sources adequate for aquaculture (Albert and Marc, 2008). A major obstacle is the effects of alternative plant-based diets on the intestinal structure, inflammation, reduced growth as well as nutrient digestion and absorption, and an increased susceptibility to disease ( $\AA$ shild et al., 2010). Plant ingredients, such as wheat gluten meal (WGM), have been used previously in the manufacturing of aquaculture diets (Messina et al., 2013; Pfeffer et al., 2010; Davies et al., 2015). WGM is known to contain high-quality protein source, is highly digestible, and without anti-nutritional substances (Apper-Bossard et al., 2013). Replacement of FM with WGM in aquaculture diets is economically desirable, but the effects of WGM on the intestinal morphology and microbiota of large yellow croaker are poorly understood.

Various culture-based techniques have been used to elucidate the structure and dynamics of the intestinal microbiota of fish (Cahill, 1990). Recently, rapid and low cost next-generation sequencing approaches have been introduced to study the composition and genetic potential of densely populated microbial communities such as gut microbiota (Foster et al., 2012). Within the past few years, these techniques have been applied to analyze the composition and functional properties of fish microbial communities. The 454/Roche pyrosequencing and Illumina technologies have also been used to characterize both dominant and low abundance microbial communities (Star et al., 2013; Wong et al., 2013).

Large yellow croaker (Larimichthys Crocea) is one of the most important mariculture fish in China (Yi et al., 2014). The nutritional researches of large yellow croaker have made some achievements (Ai et al., 2006; Asino et al., 2011; Wang et al., 2017). The aim of this study was to reveal the intestinal response of juvenile large yellow croaker fed with a practical WGM based diet. The aim of the present study was on the conditions of the intestinal morphology and microbiota community under different dietary plant protein levels.

\section{Experimental diets.}

\section{Materials and Methods}

Five experimental diets were formulated to be isonitrogenous (450 g kg-1 crude protein) and isolipidic (100 g kg-1 crude lipid). In the diets, wheat gluten meal (WGM) replaced 0 (the control), 91.6, 183.2, 274.7, and $366.3 \mathrm{~g} \mathrm{~kg}-1$ of FM protein to design WGM0, WGM25, WGM50, WGM75, and WGM100, respectively, supplemented with crystalline amino acids, such as lysine and methionine. The ingredients and approximate composition of diets are presented in Table 1.

The diet production process.

The ingredients were ground using a hammer mill $(\mathrm{H}-28$, South China University of Technology, Guangzhou, China) and passed through an 80-mesh filter. The feed ingredients were thoroughly combined using a Hobart-type mixer (M-256, South China University of Technology, Guangzhou, China). Oil and water were then added to the above mixture and mixed thoroughly to produce a stiff dough. The dough was then pelleted using an experimental feed extruder (F-26 II, South China University of Technology, China). The pellets $(2.00 \mathrm{~mm}$ and $4.00 \mathrm{~mm}$ diameter) were air dried to approximately $10 \%$ moisture and then packed into vacuum bags and stored at $-20^{\circ} \mathrm{C}$. 
Table 1 Formulation and proximate composition (\% dry weight) of five experimental diets fed to juvenile large yellow croaker.

\begin{tabular}{|c|c|c|c|c|c|}
\hline \multirow[b]{2}{*}{ Ingredients } & \multicolumn{5}{|c|}{ Diets $\left(g \mathrm{~kg}^{-1}\right)$} \\
\hline & WGMO & WGM25 & WGM50 & WGM75 & WGM100 \\
\hline Fish meal $^{a}$ & 400.00 & 300.00 & 200.00 & 100.00 & 0.00 \\
\hline Wheat gluten meal & 0.00 & 91.6 & 183.2 & 274.7 & 366.3 \\
\hline Soy bean meal & 289.6 & 289.6 & 289.6 & 289.6 & 289.6 \\
\hline Wheat-starch & 160.00 & 160.00 & 160.00 & 160.00 & 160.00 \\
\hline Cellulose & 27.9 & 14.1 & 10.4 & 6.6 & 3.0 \\
\hline Fish oil & 18.2 & 22.9 & 27.6 & 32.3 & 36.9 \\
\hline Soybean oil & 18.3 & 23.0 & 27.6 & 32.3 & 37.0 \\
\hline Soybean lecithin & 15 & 15 & 15 & 15 & 15 \\
\hline Vitamin premix ${ }^{b}$ & 30.00 & 30.00 & 30.00 & 30.00 & 30.00 \\
\hline Mineral premix ${ }^{c}$ & 20.00 & 20.00 & 20.00 & 20.00 & 20.00 \\
\hline Lysine & 0.00 & 1.6 & 3.2 & 4.7 & 6.3 \\
\hline Methionine & 0.00 & 1.2 & 2.4 & 3.7 & 4.9 \\
\hline Choline chloride & 3.00 & 3.00 & 3.00 & 3.00 & 3.00 \\
\hline Monocalcium phosphate & 15 & 15 & 15 & 15 & 15 \\
\hline Taurine & 0.00 & 10 & 10 & 10 & 10 \\
\hline Attractant $^{d}$ & 3.00 & 3.00 & 3.00 & 3.00 & 3.00 \\
\hline Total & 1000.00 & 1000.00 & 1000.00 & 1000.00 & 1000.00 \\
\hline \multicolumn{6}{|c|}{ Proximate analyses (\% Dry Weight) } \\
\hline Crud Protein & 452.7 & 464.2 & 470.1 & 467.5 & 479.4 \\
\hline Crud Lipid & 101.4 & 101.8 & 101.3 & 103.4 & 101.1 \\
\hline Ash & 113.5 & 97.00 & 84.20 & 69.40 & 58.20 \\
\hline
\end{tabular}

a Red fishmeal (Danish), $738.8 \mathrm{~g} \mathrm{~kg}^{-1}$ crude protein, $100.7 \mathrm{~g} \mathrm{~kg}^{-1}$ crude lipids, $184.1 \mathrm{~g} \mathrm{~kg}^{-1}$ ash; fermented soybean meal (Ningbo, China), $522.4 \mathrm{~g} \mathrm{~kg}^{-1}$ crude protein, $20.3 \mathrm{~g} \mathrm{~kg}^{-1}$ crude lipids, 35.2 $\mathrm{g} \mathrm{kg}^{-1}$ ash; wheat gluten meal ( Ningbo, China) , $806.8 \mathrm{~g} \mathrm{~kg}^{-1}$ crude protein, $17.6 \mathrm{~g} \mathrm{~kg}^{-1}$ crude lipids, $7 \mathrm{~g} \mathrm{~kg}^{-1}$ ash.

b Supplied the following ( $\mathrm{mg} \mathrm{kg}^{-1} \mathrm{or} \mathrm{g} \mathrm{kg}^{-1}$ diet): thiamin $25 \mathrm{mg}$; riboflavin, $45 \mathrm{mg}$; pyridoxine $\mathrm{HCL}$, $20 \mathrm{mg}$; vitamin $\mathrm{B} 12,0.1 \mathrm{mg}$; vitamin $\mathrm{K} 3,10 \mathrm{mg}$; inositol, $800 \mathrm{mg}$; pantothenic acid, $60 \mathrm{mg}$; niacin acid, $200 \mathrm{mg}$; folic acid, $20 \mathrm{mg}$; biotin, $1.20 \mathrm{mg}$; retinol acetate, $32 \mathrm{mg}$; cholecalciferol, 5 $\mathrm{mg}$; alpha-tocopherol, $120 \mathrm{mg}$; ascorbic acid, $2000 \mathrm{mg}$; choline chloride, $2500 \mathrm{mg}$; ethoxyquin, $150 \mathrm{mg}$; and wheat middling, $14.012 \mathrm{~g}$.

c Supplied the following (mg kg-1 or g kg-1 diet): NaF, 2 mg; KI, $0.8 \mathrm{mg} ; \mathrm{CoCl}_{2} .6 \mathrm{H}_{2} \mathrm{O}(1 \%), 50 \mathrm{mg}$; $\mathrm{CuSO}_{4} .5 \mathrm{H}_{2} \mathrm{O}, 10 \mathrm{mg} ; \mathrm{FeSO}_{4} \cdot \mathrm{H}_{2} \mathrm{O}, 80 \mathrm{mg} ; \mathrm{ZnSO}_{4} \cdot \mathrm{H}_{2} \mathrm{O}, 50 \mathrm{mg} ; \mathrm{MnSO}_{4} \cdot \mathrm{H}_{2} \mathrm{O}, 60 \mathrm{mg} ; \mathrm{MgSO}_{4} .7 \mathrm{H}_{2} \mathrm{O}$, $1200 \mathrm{mg} ; \mathrm{Ca}\left(\mathrm{H}_{2} \mathrm{PO}_{3}\right)_{2} . \mathrm{H}_{2} \mathrm{O}, 3000 \mathrm{mg} ; \mathrm{NaCl}, 100 \mathrm{mg}$; Zoelite, $15.447 \mathrm{~g}$. 
${ }^{d}$ Supplied the following (\% diet): glycine and betaine (1:2).

The fish culturing process.

The fish were obtained from a commercial farm at Xiangshan Bay (Ningbo, P.R. China). Prior to the start of the trial, the fish were transported to floating sea cages ( $3 \mathrm{~m} \times 3 \mathrm{~m} \times$ $3 \mathrm{~m}$ ) for 2 weeks of acclimatization. We fed a commercial diet containing $45 \%$ crude protein and $10 \%$ crude lipid during the acclimatization (Ningbo Techbank Aquafeed Company, Ningbo, P.R. China). At the start of the experiment, the fish were fasted for $24 \mathrm{~h}$ before weighing. Fish of similar sizes (initial weight $10.45 \pm 0.01 \mathrm{~g}$, mean \pm S.E.M.) were distributed into 18 fish cages, with 60 fishes per cage. Each diet was randomly tested in triplicate in a feeding trial of 8 weeks. Fish were manually fed to apparent satiation twice (05:00-07:00 and 17:00-19:00) daily. The amount of consumed diet was recorded daily. During the experimental period, the water temperature ranged from 26.0 to $31.5^{\circ} \mathrm{C}$, salinity 32 to $36 \%$, dissolved oxygen 5.6 to $6.5 \mathrm{mg} \mathrm{L}^{-1}$, and $\mathrm{pH} 7.9$ to 8.1 .

Zootechnical parameters.

At the start and termination of the experiment, the total number and mean body weight of fish in each cage were determined. At the termination of the experiment (56-d feeding trial), the fish were fasted for $24 \mathrm{~h}$ before harvest.

Survival $(\%)=100 \times$ (final amount of fish / initial amount of fish)

Weight gain ratio $\left(W_{G R} \%\right)=\left(W_{t}-W_{0}\right) / W_{0}$

Specific growth rate $(S G R, \% /$ day $)=100 \times\left[\ln W_{t}-\ln W_{0}\right] / t$

Feed conversion ratio $(\mathrm{FCR}, \%)=$ dry feed intake $/\left(\mathrm{W}_{\mathrm{t}}-\mathrm{W}_{0}\right)$

$W_{t}$ and $W_{0}$ represent the final and initial weights of large yellow croaker, while $t$ represents the rearing days.

\section{Intestinal histology}

The intestinal histology process was as described in (Wang et al., 2019).

Intestinal microbiology. At the end of the trial, six fish per treatment were sampled to investigate the intestinal microbiota. The intestinal tract was aseptically removed according to the protocol described previously (Merrifield et al., 2009) and incubated in $70 \%$ molecular grade ethanol, and stored at $-80^{\circ} \mathrm{C}$ until further analysis.

The intestinal high-throughput analyses were according to (Wang et al., 2019).

\section{Statistical analysis}

All data were subjected to analysis of variance using SPSS 17.0 for Windows. Differences among the means were tested by Tukey's multiple range tests. The level of significance chosen was $\mathrm{P}<0.05$.

\section{Zootechnical parameters}

\section{Results}

The effects of diets on survival, SGR (specific growth rate), WGR (weight gain ratio), and FCR (feed conversion ratio) are shown in Table 2. There were no significant differences in the survival and FCR after treatment $(P>0.05)$. Fish fed with diets of WGM25, WGM50, and WGM75 had significantly higher SGR and WGR compared to those fed with WGMO ( $P$ $<0.05)$; fish fed with WGM50 exhibited the highest SGR and WGR.

Intestinal histology. The results of the histological evaluation are presented in Table 3. There were no significant differences in mucosal thickness (MT), lamina propria width (LW), mucosal fold height ( $\mathrm{MH})$, and goblet cell quantity of single hair (GC) after feeding the diets $(P>0.05)$.

\section{High-throughout sequencing}

We got altogether 192,267 reads from the digesta post QC. Good's coverage rarefaction curves for all individual samples WGM0 (TC the control group), WGM50 (TB the best growth group), and WGM100 (TW the worst growth group) reached a plateau close to 1 (i.e. 
0.99948-0.99957) (Table 4), which indicated that sufficient coverage was achieved and that the OTUs detected in the samples were representatives of the sampled population.

To compare the bacterial diversity obtained after different treatments, Shannon (Table 4) was used the OTUs. The Shannon index was estimated to be 2.69 after the TC treatment, 2.76 after the TB treatment, and 2.64 after the TW treatment. The Shannon index in TW was lower, suggesting that higher WGM content led to lower intestinal bacterial diversity. However, no significant difference in diversity indices was detected.

Effects of dietary WGM on the intestinal bacterial composition

To examine the effects of WGM on intestinal microflora of juvenile large yellow croaker, samples from control group (fed with WGM0), the group fed with WGM50, and the worst group (fed with WGM100) were analyzed. A total of 69 operational taxonomic units (OTUs) were observed, of which 50 OTUs $(72.46 \%)$ were common for all the three treatments (Figure 1). the common OTUs in TC (WGM0) and TB (WGM50) groups were 55, accounting for 80.88\%; the common OTUs in TW (WGM100) and TB (WGM50) groups were 56, accounting for $83.58 \%$; and the common OTUs in TW (WGM100) and TC (WGM0) groups were 52 , accounting for $78.79 \%$ of total OTUs. The numbers of unique OTUs for TC (WGM0), TB (WGM50), and TW (WGM100) groups were 2, 3, and 1, respectively (Figure 1)

The majority of reads derived from the intestine samples belonged to members of Firmicutes (81.03 94.03\%) and Proteobacteria (5.93 18.95\%). Rest of reads belonging to less abundant phyla, including Actinobacteria, Bacteroidetes, Cyanobacteria (Figure 2). Many reads derived from the water samples belonged to members of Proteobacteria (88.3\%).

Compared with the TC (the control group WGM0) group, the abundance of Firmicutes increased significantly in the TW (the worst growth group WGM100) group, and the abundance of Proteobacteria decreased significantly in the TW (WGM100) group $(P<0.05)$ (Figure 3).

It can be seen from the figure that there was a higher correlation between

SGR and Lysobacter, Lactobacter, Fusobacter; Dermacoccus was highly correlated with LYZ; Acinetobacter and Pseudomonas were highly correlated with AKP and C4 (Figure 4).

Table 2 Growth performance, feed utilization, and survival of juvenile large yellow croaker fed with WGM diets for 56 days.

\begin{tabular}{llllll}
\hline & \multicolumn{5}{c}{ Diets } \\
\cline { 2 - 6 } & WGMO & WGM25 & WGM50 & WGM75 & WGM100 \\
\hline SGR & $2.25 \pm 0.06^{\mathrm{a}}$ & $2.48 \pm$ & $2.58 \pm 0.02^{\mathrm{c}}$ & $2.49 \pm$ & $2.37 \pm$ \\
(\%/day) & & $0.03^{\mathrm{bc}}$ & & $0.04^{\mathrm{bc}}$ & $0.01^{\mathrm{ab}}$ \\
WGR (\%) & $2.54 \pm 0.13^{\mathrm{a}}$ & $3.01 \pm$ & $3.23 \pm 0.05^{\mathrm{c}}$ & $3.03 \pm$ & $2.78 \pm$ \\
& & $0.06^{\mathrm{bc}}$ & & $0.08^{\mathrm{bc}}$ & $0.02^{\mathrm{ab}}$ \\
FCR (\%) & $1.48 \pm 0.12$ & $1.56 \pm 0.20$ & $1.28 \pm 0.09$ & $1.29 \pm 0.04$ & $1.36 \pm 0.05$ \\
Survival & $94.45 \pm 4.01$ & $75.56 \pm$ & $88.33 \pm$ & $90.00 \pm$ & $94.45 \pm$ \\
(\%) & & 8.73 & 5.85 & 3.47 & 4.01 \\
\hline
\end{tabular}

Data represent mean \pm S.E.M $(n=3)$. Values in the same column with different superscripts represent significant difference $(p<0.05)$, Values in the same row with same or no superscripts do not have significant difference $(p>0.05)$. 
Table 3 The effects of dietary WGM on the intestinal structural parameters of juvenile large yellow croaker after 56 days of growth.

\begin{tabular}{cccccc}
\hline & \multicolumn{5}{c}{ Diets } \\
\cline { 2 - 6 } & WGM0 & WGM25 & WGM50 & WGM75 & WGM100 \\
\hline \multirow{2}{*}{$\mathrm{MT}(\mu \mathrm{m})$} & $118.74 \pm$ & $126.70 \pm$ & $169.29 \pm$ & $129.02 \pm$ & $142.66 \pm$ \\
& 20.23 & 27.25 & 35.53 & 25.06 & 18.25 \\
$\mathrm{LW}(\mu \mathrm{m})$ & $5.96 \pm$ & $3.91 \pm$ & $4.61 \pm$ & $5.70 \pm$ & $9.87 \pm$ \\
& 0.93 & 0.51 & 0.62 & 0.55 & 0.36 \\
$\mathrm{MH}(\mu \mathrm{m})$ & $2.95 \pm$ & $4.31 \pm$ & $3.49 \pm$ & $4.06 \pm$ & $3.24 \pm$ \\
& 0.49 & 0.08 & 0.47 & 0.23 & 0.40 \\
$\mathrm{GC}$ & $2.62 \pm$ & $2.44 \pm$ & $2.73 \pm$ & $4.33 \pm$ & $2.56 \pm$ \\
& 0.59 & 0.25 & 1.28 & 2.52 & 0.33 \\
\hline
\end{tabular}

Table 4 Good's coverage, richness (Chao 1), observed species, and diversity index (Shannon) of intestinal microbiota composition in juvenile large yellow croaker after 56 days.

\begin{tabular}{lclll}
\hline & Chao1 index & Good's coverage & $\begin{array}{l}\text { Observed } \\
\text { species }\end{array}$ & Shannon index \\
\hline WGM0 & $56.50 \pm 2.02$ & $\begin{array}{l}0.99957 \pm \\
0.000027\end{array}$ & $45.33 \pm 1.45$ & $2.69 \pm 0.004$ \\
WGM50 & $56.28 \pm 1.64$ & $\begin{array}{l}0.99949 \pm \\
0.000016\end{array}$ & $47.67 \pm 1.20$ & $2.76 \pm 0.070$ \\
WGM100 & $63.45 \pm 6.67$ & $\begin{array}{l}0.99948 \pm \\
0.000082\end{array}$ & $45.67 \pm 1.33$ & $2.64 \pm 0.002$ \\
\hline
\end{tabular}

Note: The mean values of Cd52, Cd53, and Cd54 indicates WGM0 in control group; the mean value of Cd61, 396 Cd62, and Cd63 indicates TB in WGM50 which exhibits relatively the best growth; the mean value of Cd64, Cd65 397 and Cd66 indicates TB in WGM100 which exhibits relatively the worst growth. 


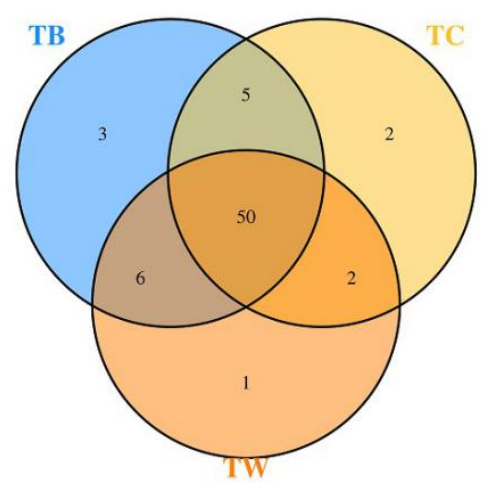

Figure 1 Venn diagram showing the unique and shared OTUs in Control (TC), WGM50 (TB), and WGM100 (TW) groups.

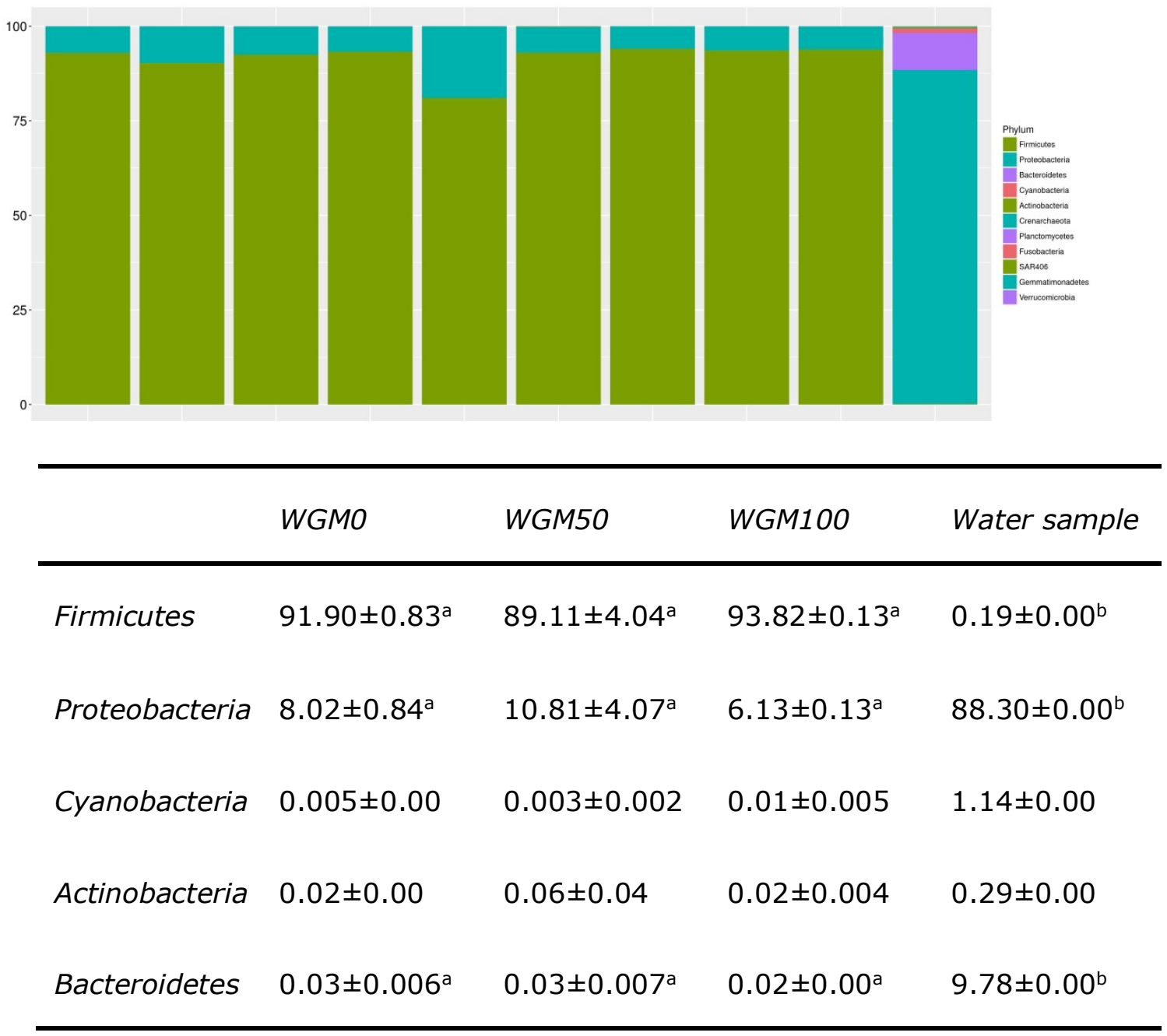

Figure 2 Frequency distribution (\%) of bacterial phyla in the intestine of juvenile large yellow croaker. 


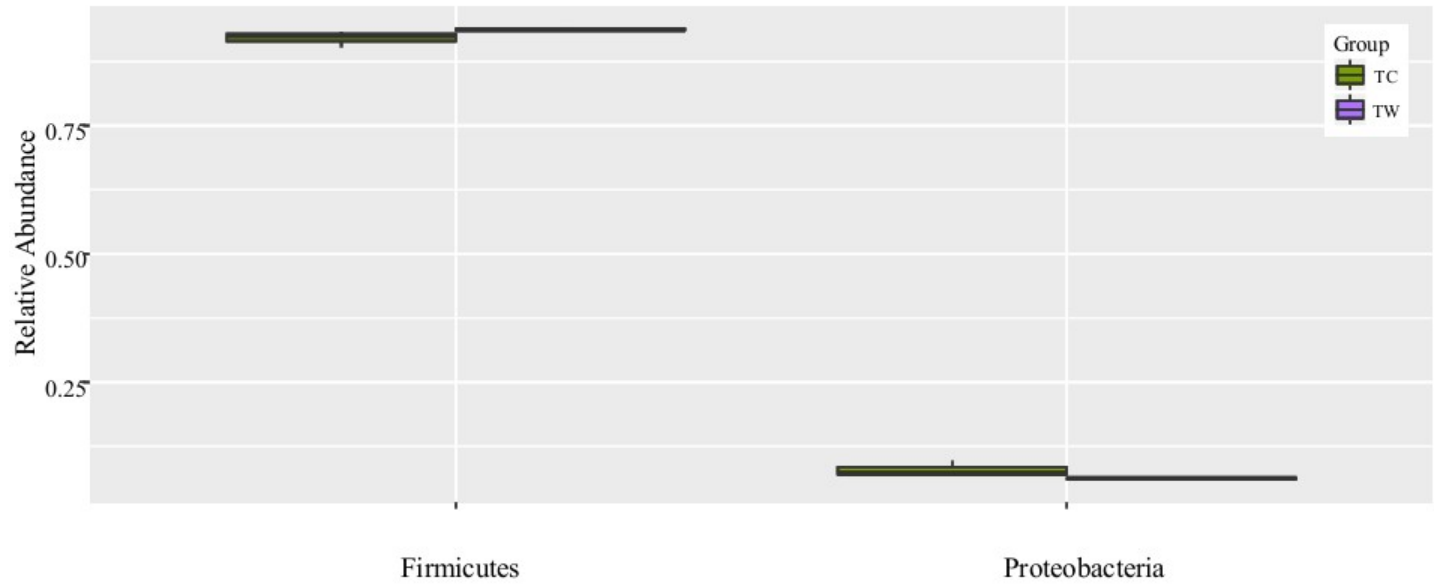

Figure 3 Comparison between the different treatments at the phyla level

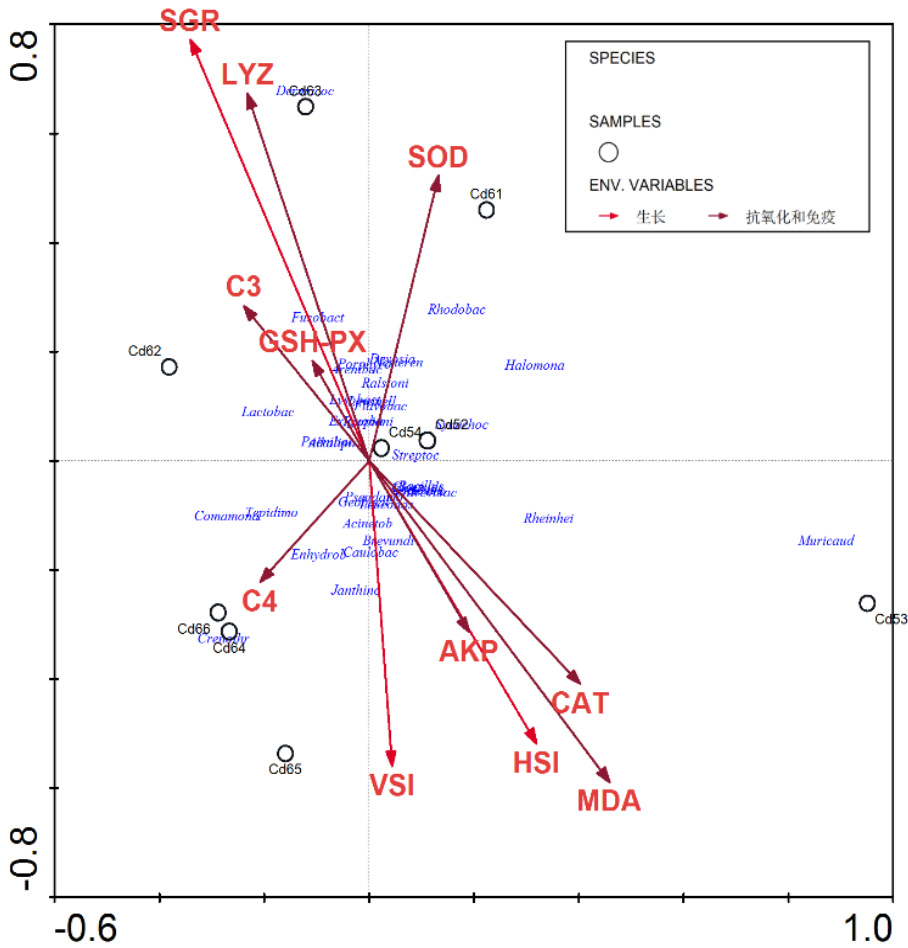

Figure 4 Correlation of gut microbes and growth, antioxidants, and immunity of juvenile large yellow croaker. The arrow indicates the environmental factors (i.e., growth and immunity); the arrow quadrant shows the positive and negative relationship between environmental factors and axes; and arrow length represents an environmental factor and the research object distribution degree, the longer the line, the bigger the influence of environmental factors on the distribution of the objects. Correlation between the arrowhead connection and the ranking axis represents correlation between the environmental factor and the sort axis. The smaller the angle, the higher the correlation. 


\section{Discussion}

The experimental diets had no significant effects on the survival of juvenile large yellow croaker. This was possibly due to a lack of any nutritional deficiencies in the experimental diets, which indicated that WGM could be an adequate source of plant protein. The health promoting properties of WGM have been studied extensively (Draganovic et al., 2011), and previous studies have reported that WGM supplementing in diets enhanced the growth performances of Atlantic halibut (Hippoglossus hippoglossus) (Helland and Grisdalehelland, 2006) and rainbow trout (Davies et al., 2015). In our study, the replacement of FM with WGM in the diet of juvenile large yellow croaker promoted the SGR. This was an indication that complete replacement of FM with WGM was also feasible in juvenile large yellow croakers during a short culture period. This might be due to addition of palatability enhancer and balanced amino acids in the diet.

The intestine is an organ responsible for nutrient absorption, barrier functions, signal recognition, and the production of endogenous active molecules. The intestinal wall of fish consists of four layers: mucosa, sub-mucosa, muscularis, and serosa (Cerezuela et al., 2013). The intestinal mucosa consists of a simple epithelium and a lamina propria. The epithelium comprises a single layer of enterocytes interspersed with mucous-secreting goblet cells and various leucocytes (Apper et al., 2016). The single-cell layer of intestinal epithelium plays a key role in nutrient digestion and absorption and forms the most important barrier between the internal and external environment. The ability of the intestinal epithelium to act as an environmental barrier is essential for maintaining the health of the organism (Abdelqader and Al-Fataftah, 2016). In the present study, intestinal integrity was not significantly affected by WGM administration in the juvenile large yellow croaker, which was in close agreement with previous studies reporting only minor alterations (Apper et al., 2016). This result was obtained probably due to the high content of glutamine in wheat proteins, which is a major substrate for all rapidly proliferating cells and plays an important role in maintaining intestinal trophicity (Apperbossard et al., 2013). Two studies recently demonstrated that glutamine significantly increases enterocyte abundance and microvilli length in catfish (Ictalurus punctatus) intestine (Pohlenz et al., 2012), and improved growth performance and intestinal digestion/absorption ability of young hybrid sturgeon (Qiyou et al., 2011).

The commensal gut microbiota is highly important for normal functioning of the immune apparatus of the GI tract in fish (Ringø et al., 2016). Although the composition of endogenous microbiota depends on genetic, nutritional, and environmental factors, it is generally accepted that

Gram-negative facultative anaerobic bacteria constitute the predominant endogenous microbiota in a variety of species of marine fish (Gómez and Balcázar, 2008). In this study, we found that all of the individual aquacultured juvenile large yellow croaker possessed similar intestinal bacterial communities dominated by a large shared core microbiota comprising of 50 OTUs. Moreover, the relative abundances of most of these shared OTUs were largely unaffected by the experimental alterations in diet. Firmicutes and Proteobacteria were predominant bacterial groups in each sample based on the Illumina sequencing data. This result was consistent with previous reports about the gut microbial communities in grass carp (Wu et al., 2012), rainbow trout (Wong et al., 2013), and many other species of fish (Sullam et al., 2012), indicating that members of these bacterial groups are essential and well adapted to intestinal environments in fish. The impact on gut microbiota varied on the basis of the WGM levels. Primarily, significantly higher abundance of Firmicutes was observed in TW than it in TC, and lower abundance of Proteobacteria was observed in TW than it in TC. A possible explanation is that the Proteobacteria and Firmicutes groups identified in this study were sensitive to some nutrients from the WGM. WGM contains fewer amounts of non-starch polysaccharides (NSPs); therefore, complete replacement of FM by WGM in group TW resulted in obvious enrichment of Firmicutes, indicating that these bacterial groups were associated with NSP degradation. Previous reports demonstrated that many species of Firmicutes are NSP-degrading bacteria (Pankratov et al., 2006; Flint et al., 2008). 


\section{Conclusion}

Overall, the paper studied the intestinal microbiota of juvenile large yellow croaker. Firmicutes and Proteobacteria were the mainly microbiota in fish which were fed with WGM and it was similar to that of other healthy marine fish. Our results indicated that up to $366.3 \mathrm{~g} \mathrm{~kg}-1$ of FM can be replaced by WGM without significantly affecting on growth performance or intestinal integrity of juvenile large yellow croaker.

\section{Acknowledgements}

This work was supported by Blue granary science and technology innovation project (2019YFD0900901); Public Welfare Technology Application Research Program of Zhejiang Province (LGN20C190011); Science and Technology Program of Zhoushan Province (2020C21008); Science and Technology Innovation Program for college students in Zhejiang Province (2019R411002).

\section{References}

Abdelqader, A., Al-Fataftah, AR., 2016. Effect of dietary butyric acid on performance, intestinal morphology, microflora composition and intestinal recovery of heat-stressed broilers. Livestock Science. 183: 78-83. DOI: 10.1016/j.livsci.2015.11.026

Ai. Q., Mai, K., Tan, B., Xu, W., Duan, Q., Ma, H., Zhang, L., 2006. Replacement of fish meal by meat and bone meal in diets for large yellow croaker, Pseudosciaena crocea. Aquaculture. 260: 255-263. DOI: 10.1016/j.aquaculture.2006.06.043

Albert, T., Marc, M., 2008. Global overview on the use of fish meal and fish oil in industrially compounded aquafeeds: Trends and future prospects. Aquaculture. 285:146158. DOI: $10.1016 /$ j.aquaculture.2008.08.015

Apper, E., Weissman, D., Respondek, F., Guyonvarch, A., Baron, F., Boisot, P., Merrifield, D L., 2016. Hydrolysed wheat gluten as part of a diet based on animal and plant proteins supports good growth performance of Asian seabass (Lates calcarifer), without impairing intestinal morphology or microbiota. Aquaculture.453: 40-48. https://doi.org/10.1016/j.aquaculture.2015.11.018

Apper-Bossard, E., Feneuil, A., Wagner, A., Respondek, F., 2013. Use of vital wheat gluten in aquaculture feeds. Aquatic Biosystems. 9: 1-13. doi: 10.1186/2046-9063-9-21

Asino, H., Ai, Q., Mai, K., 2011. Evaluation of Enteromorpha prolifera as a feed component in large yellow croaker (Pseudosciaena crocea, Richardson, 1846) diets. Aquaculture Research. 42: 525-533. https://doi.org/10.1111/j.1365-2109.2010.02648.x

Åshild, K., Michael, P., Jim, T., Ståle, R., Annemarie, B., 2010. Important antinutrients in plant feedstuffs for aquaculture: an update on recent findings regarding responses in salmonids. Aquaculture Research. 41: 333-344.

Cahill, MM., 1990. Bacterial flora of fishes: A review. Microbial Ecology. 19: 21-41. Cerezuela, R., Fumanal, M., Tapia-Paniagua, ST., Meseguer, J., Moriñigo, MÁ., Davies, SJ., Morris, PC., Baker, RTM., 2015. Partial substitution of fish meal and full. fat soya bean meal with wheat gluten and influence of lysine supplementation in diets for rainbow trout, Oncorhynchus mykiss (Walbaum). Aquaculture Research. 28: 317-328.

Draganovic, V., vander, Goot AJ., Boom, R., Jonkers, J., 2011. Assessment of the effects of fish meal, wheat gluten, soy protein concentrate and feed moisture on extruder system parameters and the technical quality of fish feed. Animal feed science and technology. 165(3-4): 238-250.

Esteban, MÁ., 2013. Changes in intestinal morphology and microbiota caused by dietary administration of inulin and Bacillus subtilis in gilthead sea bream (Sparus aurata L.) specimens. Fish \& shellfish immunology. 34(5): 1063-1070.

FAO., 2016. The State of Food Insecurity in the World 2015. Meeting the 2015 international hunger targets: taking stock of uneven progress. Food and Agriculture Organization Publications. Rome.

Flint, HJ., Bayer, EA., Rincon, MT., Lamed, R., White, BA., 2008. Polysaccharide utilization by gut bacteria: potential for new insights from genomic analysis. Nature Reviews Microbiology. 6(2), 121. 
Foster, JA., Bunge, J., Gilbert, JA., Moore, JH., 2012. Measuring the microbiome: perspectives on advances in DNA-based techniques for exploring microbial life. Briefings in Bioinformatics. 13: 420-429.

Gómez, GD., Balcázar, JL., 2008. A review on the interactions between gut microbiota and innate immunity of fish. FEMS Immunology \& Medical Microbiology. 52(2): 145-154.

Helland, SJ., Grisdale-Helland, B., 2006. Replacement of fish meal with wheat gluten in diets for Atlantic halibut (Hippoglossus hippoglossus): Effect on whole-body amino acid concentrations. Aquaculture. 261(4): 1363-1370.

Merrifield, DL., Dimitroglou, A., Bradley, G., Baker, RT., Davies, SJ., 2009. Soybean meal alters autochthonous microbial populations, microvilli morphology and compromises intestinal enterocyte integrity of rainbow trout, Oncorhynchus mykiss (Walbaum). Journal of Fish Diseases. 32: 755-766.

Messina, M., Piccolo, G., Tulli, F., Messina, CM., Cardinaletti, G., Tibaldi, E., 2013. Lipid composition and metabolism of European sea bass (Dicentrarchus labrax L.) fed diets containing wheat gluten and legume meals as substitutes for fish meal. Aquaculture. 376379: 6-14.

Pankratov, Y., Lalo, U., Verkhratsky, A., North, RA., 2006. Vesicular release of ATP at central synapses. Pflügers Archiv. 452(5): 589-597.

Pfeffer, E., Kinzinger, S., Rodehutscord, M., 2010. Influence of the proportion of poultry slaughter by-products and of untreated or hydrothermically treated legume seeds in diets for rainbow trout, Oncorhynchus mykiss (Walbaum), on apparent digestibilities of their energy and organic compounds. Aquaculture Nutrition. 1: 111-117.

Pohlenz, C., Buentello, A., Mwangi, W., Gatlin, III DM., 2012. Arginine and glutamine supplementation to culture media improves the performance of various channel catfish immune cells. Fish \& shellfish immunology. 32(5): 762-768.

Qiyou, X., Qing, Z., Hong, X., Changan, W., Dajiang, S., 2011. Dietary glutamine supplementation improves growth performance and intestinal digestion/absorption ability in young hybrid sturgeon (Acipenser schrenckii $\$ \times$ Huso dauricus $0^{7}$ ). Journal of Applied Ichthyology. 27(2): 721-726.

Ringø, E., Zhou, Z., Vecino, JG., Wadsworth, S., Romero, J., Krogdahl, A.., Owen, M., 2016. Effect of dietary components on the gut microbiota of aquatic animals. A neverending story. Aquaculture Nutrition. 22(2): 219-282.

Star, B., Haverkamp, TH., Jentoft, S., Jakobsen, KS., 2013. Next generation sequencing shows high variation of the intestinal microbial species composition in Atlantic cod caught at a single location. BMC Microbiology. 13: 1-6.

Sullam, KE., ESSINGER, SD., LOZUPONE, CA., O'CONNOR, MP., ROSEN, GL., KNIGHT, R., KILHAM, SS., RUSSELL, JA., 2012. Environmental and ecological factors that shape the gut bacterial communities of fish: a meta-analysis. Molecular Ecology . 21: 3363-3378.

Wang, P., Zhou, QC., Feng, J., He, JJ., Lou, YD., Zhu, JQ., 2019. Effects of dietary fermented soybean meal on growth, intestinal morphology and microbiota in juvenile large yellow croaker Larimichthys crocea. Aquaculture Research. 1-10.

Won,g S., Waldrop, T., Summerfelt, S., Davidson, J., Barrows, F., Kenney, PB., Welch, T., Wiens, GD., Snekvik, K., Rawls, JF., 2013. Aquacultured rainbow trout (Oncorhynchus mykiss) possess a large core intestinal microbiota that is resistant to variation in diet and rearing density. Applied \& Environmental Microbiology. 79: 49744984.

Wu, S., Wang, G., Angert, ER., Wang, W., Li, W., Zou, H., 2012. Composition, diversity, and origin of the bacterial community in grass carp intestine. PloS one.7(2): e30440.

Yi, X., Zhang, F., Xu, W., Li, J., Zhang, W., Mai, K., 2014. Effects of dietary lipid content on growth, body composition and pigmentation of large yellow croaker Larimichthys croceus. Aquaculture. 434: 355-361. 